\section{Allergenextrakte: Standardisierung notwendig}

Jeder Hersteller von Allergenextrakten gibt den Allergengehalt in eigenen Einheiten an. Bochumer Allergologen verglichen die Allergengehalte in Graspollenextrakten für Hauttests und die sublinguale Immuntherapie.

$B_{\text {fimingen }}$ ochumer Allergologen untersuchten fünf Pricktest- und zehn sublinguale spezifische Immuntherapie (SLIT)-Produkte mit Extrakten von Phleum pratense hinsichtlich Protein-, Allergen- und Majorallergengehalt. Um die Übereinstimmung verschiedener Untersuchungsmethoden überprüfen zu können, verwendeten sie für die Bestimmung von Proteinund Allergengehalt den Bradford Assay, ermittelten die Hemmung der IgE-Bindung im ImmunoCAP-Test und den $\mathrm{Ma}-$ jorallergengehalt $\mathrm{Phl}$ p 5 mithilfe eines zweiseitigen Enzym-Immunoassays.

Der Proteingehalt der Pricktestlösungen zeigte beträchtliche Unterschiede und lag zwischen $15 \mu \mathrm{g} / \mathrm{ml}$ und $427 \mu \mathrm{g} / \mathrm{ml}$, der Majorallergengehalt zwischen $0,15 \mu \mathrm{g} / \mathrm{ml}$ und $18,3 \mu \mathrm{g} / \mathrm{ml}$ (Tab. 1). Die übrigen Bestimmungen bestätigten die Rangfolge der Extrakte. Die Schwankungsbreite der Protein- und Allergengehalte der SLITProdukte war noch größer: Protein fand sich in einer Größenordnung von $5 \mu \mathrm{g}$ bis $153 \mu \mathrm{g}$, der Gehalt des Majorallergens $\mathrm{Phl}$ p 5 schwankte zwischen 0,2 $\mu \mathrm{g}$ und 21,6 $\mu$ g. Die IgE-Bindungskapazität der Erhaltungsdosis korrelierte wiederum mit dem Phl p 5- und Proteingehalt der SLITLösungen.

fk

Sander I et al. Allergen content of grass pollen preparations for skin prick testing and sublingual immunotherapy.

Allergy 2009; 64: 1486-92.

\section{Pricktestextrakte im Vergleich}

Tabelle 1

\begin{tabular}{|l|l|l|l|}
\hline Hersteller & Konzentration (laut Hersteller) & Protein $(\mu \mathrm{g} / \mathrm{ml})$ & Phl p $\mathbf{5}(\boldsymbol{\mu g} / \mathrm{ml})$ \\
\hline Allergopharma & $50.000 \mathrm{SBE} / \mathrm{ml}$ & 77 & 8,75 \\
\hline ALK-Abelló & $10 \mathrm{HEP}$ & 84 & 4,19 \\
\hline Bencard & $10.000 \mathrm{DU} / \mathrm{ml}$ & 15 & 0,15 \\
\hline HAL Allergy & $10.000 \mathrm{AU} / \mathrm{ml}$ & 427 & 18,30 \\
\hline Stallergenes & $100 \mathrm{RI}$ & 30 & 2,70 \\
\hline
\end{tabular}

\section{SLIT-Erhaltungsdosis im Vergleich}

Tabelle 2

\begin{tabular}{|c|c|c|c|}
\hline Hersteller & Produkt (Konzentration) & Protein $(\mu \mathrm{g} / \mathrm{ml})$ & Phl p $5(\mu \mathrm{g} / \mathrm{ml})$ \\
\hline LETI & Tol SL ${ }^{\oplus}(100 \mathrm{HEPL} / \mathrm{ml})$ & 5 & 0,2 \\
\hline ALK-Abelló & SLITone $^{\oplus}$ (1.000 STU/ml) & 6 & 0,2 \\
\hline Bencard & Oralvac ${ }^{\oplus}$ plus (768.000 TU/ml) & 14 & 0,6 \\
\hline Inmunotek/Roxall & Sulgen $^{\circledast}(30.000 \mathrm{TU} / \mathrm{ml})$ & 23 & 0,9 \\
\hline Themocare & Allerbio Sublingual (100 RE/ml) & 46 & 1,7 \\
\hline HAL Allergy & Sublivac $^{\circledR}(10.000 \mathrm{AU} / \mathrm{ml})$ & 56 & 3,6 \\
\hline ARTU Biologicals & $\operatorname{Igevac}^{\oplus}(9.500 \mathrm{BE} / \mathrm{ml})$ & 102 & 7,8 \\
\hline Stallergenes & Staloral ${ }^{300 ®}(300 \mathrm{IR} / \mathrm{ml})$ & 107 & 8,4 \\
\hline ALK-Abelló & $\operatorname{Grazax}^{\oplus}(75.000$ SQ-T) & $150^{*}$ & 5,0 \\
\hline Allergopharma & Allerslit ${ }^{\circledR}$ forte $(715.000 \mathrm{SE} / \mathrm{ml})$ & 153 & 21,6 \\
\hline
\end{tabular}

\section{Kommentar}

„Viel hilft viel“ ist eine alte Regel, die sich auf manchen Gebieten der Medizin bewährt hat. Im Bereich der Hyposensibilisierung ist dies umstritten. Hier kann viel Allergen auch viel Schaden anrichten, im Extremfall des anaphylaktischen Schockes auch den Tod des Patienten verursachen. Das ist auch der Grund für langwierige Titrationsschemata bei der subkutanen Hyposensibilisierung (SCIT). Während man bei der SCIT erst in den letzten Jahren versucht hat, durch Cluster-Schemata und Adjuvanzien rascher zur Erhaltungsdosis zu gelangen, ist man bei sublingualer Hyposensibilisierung schon früher mutig gewesen in der raschen Dosissteigerung und hat bei den zuerst eingeführten Sublingualtabletten sogar ganz darauf verzichtet. Dabei sind die dem Patienten oral zugeführten Allergenmengen weit höher als in der SCIT (nach Herstellerangaben 5-45-mal mehr Allergen pro Dosis) und doch ist umstritten, ob auch hier „viel viel hilft“. Eine kürzlich wegen der nachgewiesenen Therapiesicherheit der SLIT durchgeführte Metaanalyse zur Dosiswirkungsbeziehung bei der SLIT konnte in Studien keinen Zusammenhang finden. Trotzdem scheint sich ein Konsens zu etablieren, wie viele Majorallergene pro Dosis nötig sind, um so gute therapeutische Wirkungen zu erzielen, wie wir es von den zugelassenen Allergen-Produkten gewohnt sind. Dabei kann Tabelle 2 helfen.

Hilfreich ist auch die Untersuchung zum Allergengehalt von Pricktestlösungen im gleichen Artikel. Während die Lösungen der drei Marktführer ähnliche Konzentrationen von Majorallergenen und Protein aufweisen, gibt es neben einem extrem hoch dosierten Produkt auch eine Testlösung, von der die Autoren meinen, sie enthalte nahezu kein Majorallergen. Kein Wunder also, wenn bei deren Nutzung manche Patienten mit klarer Anamnese keine Reaktion im Hauttest zeigen. Wenn das häufiger auffällt, sollte man die Tabelle konsultieren und gegebenenfalls besser den Hersteller wechseln, als zum sensitiveren Intrakutantest zu greifen.

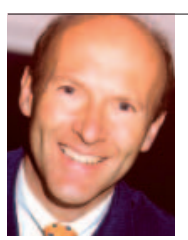

Prof. Dr. med. Ralph Mösges Institut für Medizinische Statistik, Informatik und Epidemiologie Universität Köln 